\title{
Cadena operatoria de la producción cerámica Xajay: análisis estadístico de evidencias petrográficas
}

\author{
Alejandra Castañeda Gómez del Campo, Sergey Sedov, Fernando López Aguilar, \\ Serafín Sánchez Pérez, Rubén Eduardo López Mendiola
}

\begin{abstract}
Alejandra Gastañeda Gómez del Campo alecastanedagc@gmail.com

Université Paris 1 Panthéon-Sorbonne, UMR8096- Archéologie des Amériques, 21 Allée de l'Université, 92000 Nanterre, Francia .
\end{abstract}

\section{Sergey Sedov}

Instituto de Geología, Universidad Nacional Autónoma de México, Av. Universidad \#3000, Ciudad Universitaria, Coyoacán 04510, CDMX, México.

\section{Fernando López Aguilar}

Posgrado en Arqueología, Escuela Nacional de Antropología e Historia, Periférico Sur y Zapote s/n. Colonia Isidro Fabela, Tlalpan 14030, CDMX, México.

\section{Serafín Sánchez Pérez}

Rubén Eduardo López Mendiola

Escuela Nacional de Antropología e Historia

Periférico Sur y Zapote s/n. Colonia Isidro Fabela, Tlalpan 14030, CDMX, México.

BOL. SOC. GEOL. MEX. 2019

VOL. 71 NO. 2

P. $359-381$

http://dx.doi.org/10.18268/BSGM2019v7 1n2a8

\section{RESUMEN}

El presente artículo tiene por objetivo evidenciar los elementos constitutivos de las primeras dos etapas de producción en la cadena operatoria de la cerámica de la cultura Xajay, es decir, la etapa de obtención de materias primas a partir de la identificación de los yacimientos de barro y, en segundo lugar, la etapa de preparación de las materias primas para inferir las distintas "recetas" de barro utilizadas para la elaboración de las vasijas. Asimismo, diferenciar entre la cerámica producida localmente y aquella procedente de otras regiones. La colección analizada proviene de las excavaciones realizadas en el principal centro ceremonial Xajay conocido como Pahñu, ocupado entre el 300 d. C. y el 950 d. C, localizado en municipio de Tecozautla, Hidalgo. El estudio fue realizado a partir de un análisis petrográfico (21 muestras cerámicas) y micromorfológico ( 6 muestras de suelo). El primero consistió en agrupar las muestras que compartieran una composición mineralógica para inferir una misma procedencia o yacimiento de materias primas, posteriormente se generaron subgrupos tomando en cuenta proporciones, morfología y tamaño de partículas para estudiar las distintas formas de preparación del barro. El análisis micromorfológico tuvo por objetivo la identificación y caracterización de los suelos para su posterior correlación con las muestras cerámicas. El análisis petrográfico evidenció la existencia de 4 grupos (2 locales y 2 foráneos), y 12 subgrupos de pastas (10 locales y 2 foráneos correspondientes a distintas recetas de elaboración de barro. El análisis micromorfológico permitió definir tres tipos de suelos: feozem, luvisol y vertisol. A partir de los resultados obtenidos se lograron comprender las dinámicas de explotación y preparación del barro para la elaboración de los objetos cerámicos consumidos en Pahñu. Se propone entonces que el grupo Xajay producía la mayoría de la parafernalia cerámica localizada en sus sitios, y en menor proporción obtenían cerámica producida en otras regiones (al menos dos, no determinadas en esta investigación). Dentro de los distintos tipos de suelos - vertisol, luvisol y feozem - ellos optaron por la utilización de los últimos dos.

Palabras clave: Cadenas operatorias, análisis de procedencia, cultura Xajay, cerámica, análisis petrográfico.

\section{ABSTRACT}

The purpose of this article is to explore the operational chain involved in Xajay's ceramic production through a petrographic and statistical analysis, in order to differentiate the ceramic produced locally from the one that was manufactured in other regions. The collection analyzed for this study comes from the excavations conducted in the main ceremonial center of Xajay culture, known as Pahñu, which was occupied between 300 and $950 A D$, and located in the municipality of Tecozautla, Hidalgo, Mexico. The study was based in the petrographic analysis of 21 ceramic samples, and the micromorphologic analysis of 6 soil samples. In order to review the different methods of clay preparation, the samples were first grouped by mineralogical composition to be able to infer their origin related to a same source area. In a second moment, groups were defined in subgroups, taking into consideration proportions, morphology, and size of antiplastic particles. Likewise, the purpose of the micro-morphological analysis was the identification and characterization of soils, in order to correlate soils with corresponding ceramic samples. The analysis allowes for an understanding of the dynamics involved in raw material exploitation and clay preparation for the elaboration of ceramic objects used at Pahñu. With regards to the different types of soil used in ceramic production - Vertisol, Luvisol and Feozem - the inhabitants of Pahñu opted for the latter two. The information obtained in this study leads to the conclusion that the Xajay culture produced most of their ceramic assemblage locally and acquired, to a lesser degree, ceramic produced in other regions.

Keyzords: Operational chains, provenance analysis, Xajay culture, pottery, petrographic analysis. 


\section{Introducción}

\subsection{LAS GADENAS OPERATORIAS Y LA GERÁMICA XAJAY}

La cadena operatoria en Arqueología constituye una herramienta analítica que estudia el proceso de manufactura de cualquier elemento de la cultura material, a partir de la identificación de huellas relacionadas con cada una de las etapas y gestos involucrados en el proceso de producción de un objeto (Cresswell, 1973; Leroi-Gourhan, 1971; Perlès, 1987; Sellet, 1993; Roux, 2016).

$\mathrm{Al}$ estudiarla estamos lidiando con un cuerpo de conocimientos, saberes y prácticas, válidos en un tiempo y espacio determinado, que en palabras de Leroi-Gourhan constituyen "[E]l elemento fundamental de su unidad y de su personalidad, y la transmisión de este capital intelectual es la condición necesaria para la supervivencia material y social"; a este cuerpo de conocimientos se le denomina tradición (Leroi-Gourhan, 1971). De esta manera los estudios tecnológicos por cadenas operatorias proponen que, a partir del estudio de las tradiciones tecnológicas, es posible adentrarnos en los elementos constitutivos e identitarios de cualquier unidad social.

Esta investigación se suma a los trabajos realizados en torno a la definición de la "Cultura Xajay" como una unidad social con una identidad propia (Morett, 1996; Cedeño, 1998; López et al., 1998; Sandoval, 2009; Farías, 2010, 2017; Castañeda, 2015; Mireles, 2015). En este caso la problemática será abordada a partir del análisis tecnológico de uno de los elementos que conforman su cultura material: la cerámica.

La cerámica Xajay ha sido estudiada únicamente desde un enfoque tipológico, con el objetivo de situarla temporalmente y en asociación a una serie de complejos cerámicos para el estudio de su distribución (Nalda, 1975, 1991; Saint-Charles y Argüelles, 1991; Crespo y Saint-Charles, 1996; Saint-Charles et al., 2005, 2006; Cervantes y Fournier, 1994; Avilez y Solar, 2006; Morett, 1996; Bonfil, 2006). En este sentido, este trabajo constituye la primera aproximación utilizando análisis petrográficos y micromorfológicos para su estudio. Este trabajo conforma una parte del estudio realizado para la definición de las cadenas operatorias involucradas en el proceso productivo de la cerámica consumida por el grupo Xajay en el centro ceremonial Pahñu (Castañeda, 2015) y tiene por objetivo presentar únicamente los elementos constitutivos de las primeras dos etapas de su producción, es decir, la etapa de obtención de materias primas para la localización de sus yacimientos y, en segundo lugar, la etapa de preparación de las mismas para inferir las distintas "recetas" de barro utilizadas para la elaboración de las vasijas. Asimismo, se pretende identificar la cerámica producida localmente y aquella procedente de otras regiones.

\subsection{EL ANÁLISIS PETROGRÁFICO GOMO HERRAMIENTA PARA RECONSTITUIR LA GADENA OPERATORIA}

La aplicación de herramientas geológicas y edafológicas como la petrografía y la micromorfología en problemáticas arqueológicas ha desarrollado sus fundamentos a partir de varios ejes de investigación dentro de los cuales destacan: la aplicación de estudios petrográficos enfocados en la caracterización de componentes geológicos de materiales gruesos, los cuales han tenido como principal objetivo la discriminación entre materiales foráneos y locales, así como para el estudio del manejo y transformación de los mismos (Sean Quinn, 2013). Por otro lado, la petrografía y micromorfología también han servido a aquellos estudios donde se comparan datos edafológicos con materiales geológicos para la localización de bancos de materias primas (Cabadas-Báez et al., 2017; Wieder y Adan-Bayewitz, 1999; Guerrero, 2014). Finalmente, son ejemplo de ello los estudios etnográficos aplicados a la producción cerámica, donde el estudio de materias primas utilizando micromorfología y petrografía han trazado ya un camino metodológico fiable (de la Vega, 2006, 2007; Chaves, 2005; Chaves et al., 2005; Ramos-Galicia et al., 2003). 
Por su parte, el análisis por cadenas operatorias en cerámica implica el conocimiento de las etapas mínimas de dicho proceso y el reconocimiento de las huellas plasmadas en el material relacionadas con cada una de éstas. Esto implica transitar por distintas escalas de observación, tanto macroscópicas como microscópicas, por ello, los análisis petrográficos y micromorfológicos constituyen herramientas fundamentales para adentrarnos en la comprensión de las primeras etapas de la cadena (Roux, 2016).

Bajo este marco se utilizó la petrografía como una herramienta que permitió, además de conocer las fases minerales de las partículas antiplásticas, la orientación de los minerales, su distribución en la sección analizada, sus asociaciones y también permitió identificar los componentes amorfos como el vidrio volcánico y estableció la abundancia de cada uno de estos (Sean Quinn, 2013).

$\mathrm{El}$ análisis micromorfológico de las secciones delgadas de los suelos permitió observar el arreglo de las partículas que los constituyen, es decir, las microestructuras que expresan los procesos pedogenéticos que tuvieron lugar en su desarrollo y son propias de cada tipo de suelo (Stoops, 2003). Este enfoque micromorfológico se aplicó también a las láminas delgadas de cerámica con el objetivo de identificar microestructuras que se relacionaran directamente con el yacimiento de materia prima, particularmente con los suelos. Con ello se pudieron identificar microestructuras de suelo como cutanes de arcilla o los fragmentos de estos conocidos como pápulas (Cabadas-Báez, 2017; Stoops, 2003).

Así, las preguntas que direccionaron la aplicación de dichos análisis fueron: ¿La cerámica Xajay deriva de una producción local o se trata de productos exógenos?, ¿cuál es la ubicación de las fuentes de las materias primas?, ¿cuál es la composición mineralógica de la cerámica Xajay?, ¿qué componentes del material cerámico pueden considerarse naturales (procedentes del barro) y cuáles "culturales" (agregados como desgrasantes)?, y, derivado de ésta, ¿cómo se preparaba el barro?

\section{2. Área de estudio: características arqueológicas y ambientales}

\subsection{LA GULTURA XAJAY}

La cultura Xajay se desarrolló alrededor del año 300 d. C. y se ubica espacialmente dentro del Valle del Mezquital, en el área norponiente del estado de Hidalgo, en la subcuenca delimitada por el río San Juan y Moctezuma. Esta zona actualmente abarca los municipios de Huichapan y Tecozautla, donde se localizan sus principales centros ceremoniales: Pahñu, Zethé y Zidada, edificados durante el Clásico, y Cerrito y Taxangú, del Epiclásico, todo ello aunado a los sitios habitacionales, de los que destaca "La Huesamenta" (Figura 1). Durante el inicio del Epiclásico (600 d. C.) los asentamientos Xajay se expandieron hacia la zona de mesas y barrancas ubicadas al sur del estado de Querétaro y al norte del Estado de México. La ocupación Xajay tuvo su fin hacia el año 1000 d. C., evento relacionado con el surgimiento de Tula como nuevo centro rector (López et al., 2012; Farías y Castañeda, 2014).

Pahñu es considerado el centro ceremonial de mayor importancia para el grupo Xajay y tiene dos etapas ocupacionales, la primera del 300 al 550 d. C., y la segunda del 550 al 1000 d. C. (López et al., 2012; Farías y Castañeda, 2014). Está conformado por tres conjuntos de estructuras colocados en un eje orientado a $355^{\circ}$, de los cuales el conjunto 3 (o conjunto principal) es el de mayores dimensiones y está compuesto por la Estructura Principal, colocada en el límite norte de la mesa, el Tecpan al este y la Plaza principal que delimita su límite sur con una estructura que corre en dirección este/oeste a lo largo del conjunto, denominada Estructura sur.

\subsection{EL MEDIO AMBIENTE XAJAY}

Para la Antropología de la Tecnología, la elección de ciertas materias primas en una región específica involucra el conocimiento de los recursos disponibles, es decir, el conocimiento del universo a partir 


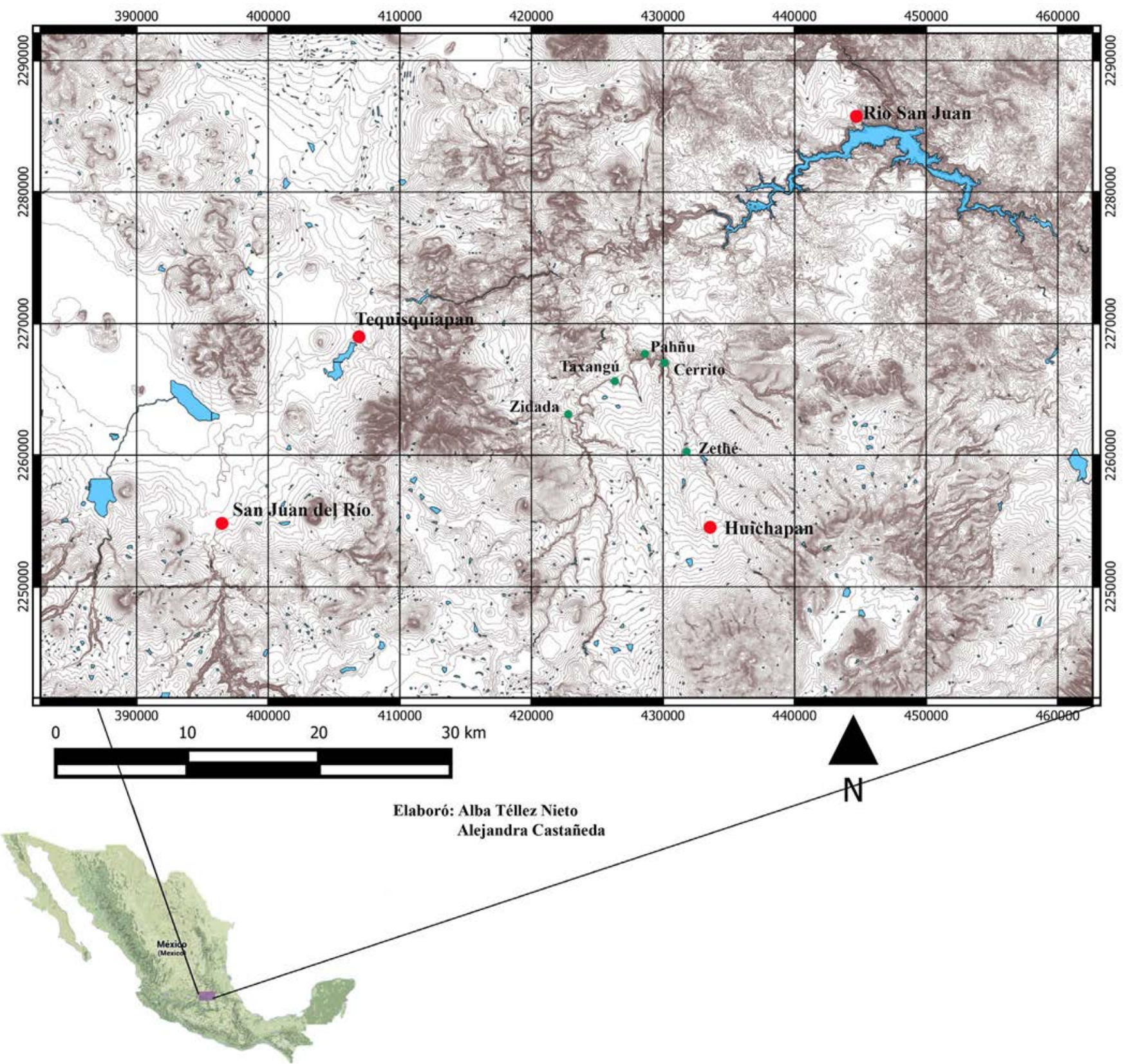

Figura 1 Ubicación del área de estudio y de los sitios Xajay.

del cual un grupo social elegirá ciertas opciones que conformarán una parte de su sistema tecnológico (Lemonnier, 1992).

Como una primera aproximación al reconocimiento del medio y al estudio de los recursos naturales, se presentarán algunas de las características geo-edafológicas del área donde se localizan los sitios Xajay.
Se reconocen al menos tres tipos de formaciones geológicas asociadas al área de asentamientos Xajay. La primera, de origen sedimentario (formación "El Doctor"), está conformada por lutitas-areniscas y calizas. La segunda, de origen volcánico, la componen basaltos y conglomerados volcánicos que contienen guijarros de andesita y riolita (Milán et al., 1993; Segerstrom, 
1961, Cortés et al., 2006). Finalmente, una tercera formación volcano-sedimentaria ácida integra la meseta sobre la cual están construidos los centros ceremoniales Xajay (conocida como formación "Toba Don Guinyó"). Asimismo, la subcuenca de Tecozautla se encuentra rodeada de formaciones montañosas compuestas por basalto que se localizan en los límites norte, oeste y sur de la región (Figura 2b). Por otro lado, los suelos presentes en la región de estudio son rendzina, luvisol, vertisol y feozem, siendo estos dos últimos los que abarcan una mayor área (Figura 2a). La relación de estos suelos con las unidades geológicas muestra que la rendzina se desarrolla sobre un sustrato de calizas; el luvisol y el feozem sobre las formaciones de toba volcánica y, finalmente, el vertisol está asociado a las formaciones de basalto-andesita.

\section{Materiales y métodos}

\subsection{MATERIALES: GORPUS DE ANÁLISIS}

La colección analizada fue obtenida a partir de las excavaciones realizadas en el principal centro ceremonial Xajay conocido como Pahñu ${ }^{1}$ (Figura 3), durante las temporadas 2011 en los edificios del conjunto principal denominados como Tecpan y Estructura Sur y 2015 en la Plaza Principal. La colección analizada está conformada por casi 6000 fragmentos cerámicos.

El material proviene de diversos estratos que conforman una serie de eventos que pueden considerarse como marcadores temporales durante la ocupación de Pahñu. Estos fueron organizados en 5 etapas ${ }^{2}:$

1. Etapa de construcción de las edificaciones del Clásico (300 d. G.).

2. Renovación del sitio (550-600 d. C.).

3. Renovación o ampliación del Epiclásico (600950 d. C.).
4. Quema del Tecpan (950 d. C.).

5. Momento de abandono y procesos post-deposicionales (950-1000 d. C.).

De esta manera el material fue registrado tomando en cuenta su temporalidad, para posteriormente poder realizar un análisis diacrónico sobre la continuidad o ruptura en cada una de las etapas de manufactura estudiadas. En la Tabla 1 se muestra la cantidad de material correspondiente a cada etapa y se integra también la relación de láminas delgadas por temporalidad.

\subsection{GRITERIOS DE MUESTREO PARA ELABORACIÓN DE LÁMINAS DELGADAS}

Con el objetivo de tener una muestra representativa respecto a la variabilidad en la composición de pastas, se eligieron aquellas que se presentaron con mayor frecuencia dentro de la colección analizada. La selección se realizó a partir de una revisión microscópica (con aumentos de 2x y 4x) de las partículas antiplásticas. De esta manera se seleccionaron un total de 21 fragmentos cerámi$\cos ^{3}$ para elaborar las láminas delgadas (Tabla 2).

\subsection{LINEAMENTOS DE LA INVESTIGACIÓN MICROSCÓPICA PARA EL ESTUDIO DE LAS MUESTRAS GERÁMICAS}

El estudio de la primera etapa, concerniente a la obtención de materias primas, tuvo por objetivo identificar los yacimientos de barro para la elaboración de los objetos cerámicos. Esto implicó la caracterización mineralógica a partir de la identificación de los componentes plásticos y antiplásticos tanto de suelos como del material cerámico. Esta primera caracterización tuvo por resultado una primera agrupación - definida como familia - que comparte los mismos componentes mineralógicos o materiales antiplásticos (Sanhueza, 2004).

${ }^{1}$ Por el Proyecto Especial Pahñu, a cargo del Dr. Fernando López Aguilar.

${ }^{2}$ En las tablas 1, 2, 9 y 10 las etapas están señaladas en la columna de temporalidad.

${ }^{3}$ Para las imágenes de cada muestra, así como la descripción detallada de las formas cerámicas identificadas, véase Castañeda, 2015. 

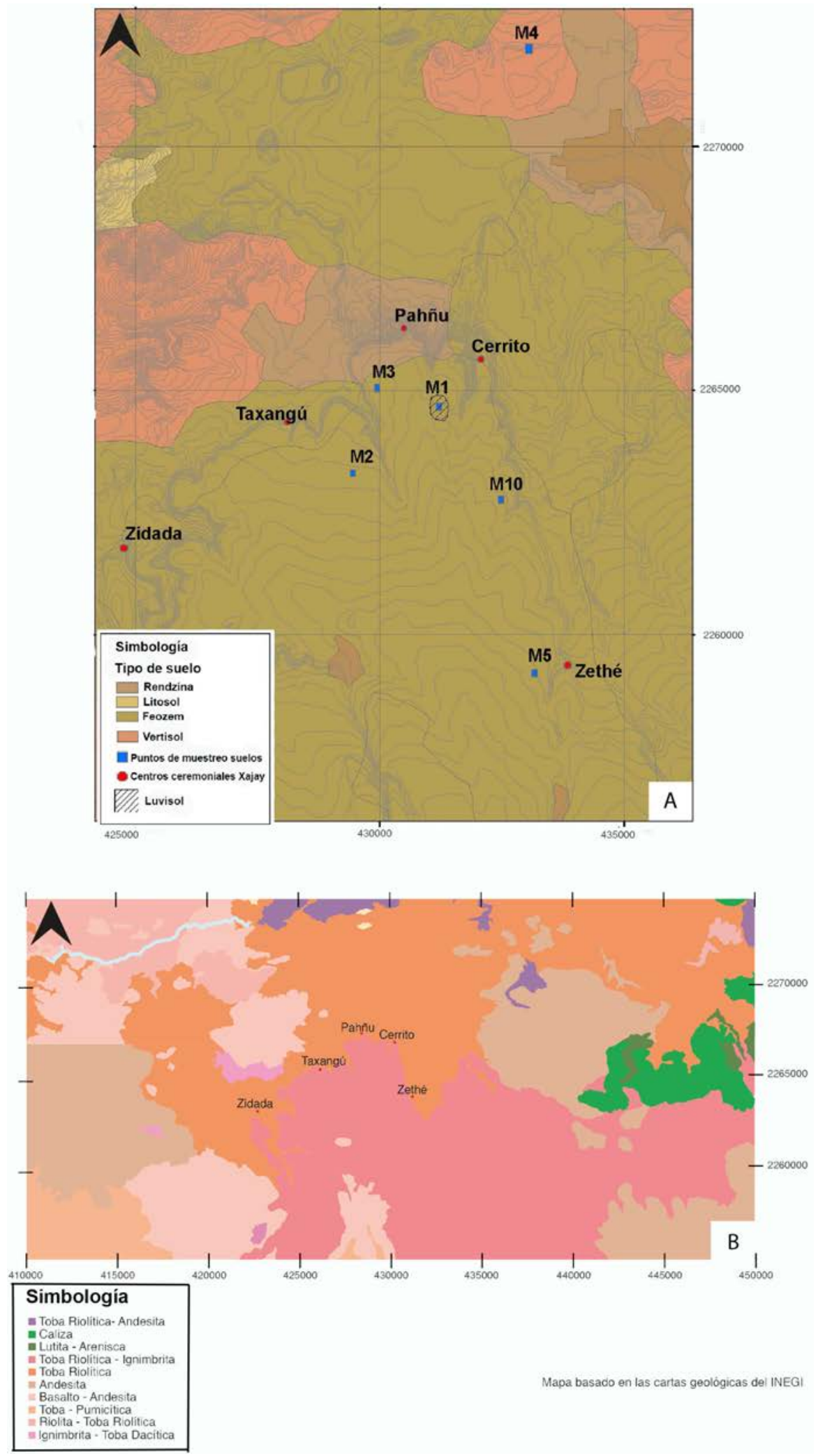

Figura 2 A) Carta edafológica (Basado en las cartas edafológicas INEGI, F14C67, F14C68, F14C77, F14C78), se muestran los puntos muestreados para el análisis micromorfológico. B) Carta geológica (Basado en las cartas geológicas INEGI, F14C67, F14C68, F14C77, F14C78). 


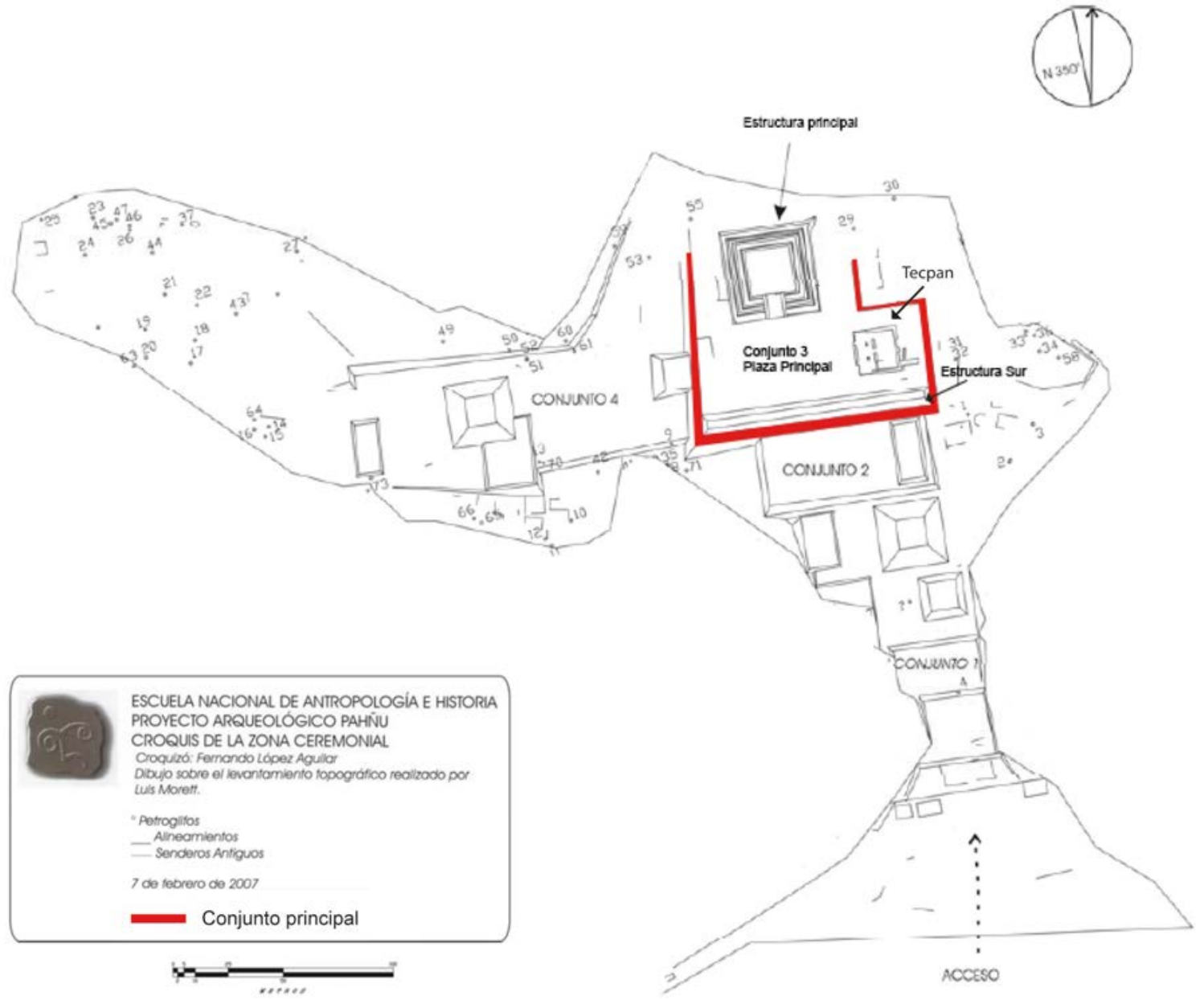

Croquis del sitio Pahñu.

Por su parte, la etapa de preparación de materias primas tuvo por objetivo la identificación de patrones en la distribución de los componentes de las pastas para inferir la manera en que fue preparado el barro. Para ello se realizó un análisis cualitativo que consistió en contabilizar cada uno de los minerales previamente identificados, así como la cantidad de matriz arcillosa a partir de un gráfico para estimación visual de porcentajes (Stoops, 2003). De esta manera se realizó una sub-división de las familias de pastas en patrones de pastas, definidos como grupos que comparten las mismas características (morfología y tamaño) y distribución (densidad) de los materiales antiplásticos (Sanhueza, 2004).

\subsection{EL ESTUDIO DE LOS SUELOS Y SU MUESTREO}

Por su parte, los suelos presentes en la región fueron caracterizados a partir de un análisis micromorfológico con un doble objetivo, primero, para evaluar si eran aptos para ser utilizados como materia prima, y segundo, para correlacionarlos con la cerámica arqueológica.

Al inicio se realizó la identificación de las unidades edáficas a partir de cartas edafológicas y geológicas; posteriormente se llevó a cabo una prospección puntual y por informantes en zonas con suelos plásticos (conocidos localmente como "pejay"). A partir de este proceso se determinó que los vertisoles, luvisoles y feozem presentaron las características necesarias para ser utilizados como 
Tabla 1. Relación de material analizado. La temporalidad corresponde con eventos relevantes acontecidos en la historia de formación del sitio Pahñu, del más antiguo (1), al más reciente (5).

\begin{tabular}{|c|c|c|c|}
\hline Temporalidad & No. Fragmentos & Porcentaje & No. Láminas delgadas \\
\hline 1 & 55 & $1.70 \%$ & 1 \\
\hline 2 & 1072 & $33.10 \%$ & 9 \\
\hline 3 & 179 & $5.50 \%$ & 0 \\
\hline 4 & 318 & $9.80 \%$ & 3 \\
\hline 5 & 1612 & $49.80 \%$ & 7 \\
\hline
\end{tabular}

materia prima en la elaboración de cerámica y fueron muestreados para su posterior análisis de laboratorio (véase Figura 2a y Tabla 3).

\subsection{ANÁLISIS ESTADÍSTICO}

En primer lugar, se estableció un Análisis de Componentes Principales (ACP), que es una técnica estadística de síntesis de la información o reducción de la dimensión (número de variables), es decir, de la amplia gama de variables que se presentan, se determinan los elementos más representativos o componentes principales y con ellos se trabaja (Terradez, 2002). Debido a la diversidad de partículas que presenta la pasta, fue necesario emplear un método estadístico multivariado que permitiera formar grupos a partir de los componentes mineralógicos identificados, para lo que se eligió el método de vinculación o linkage. La elección de este método se debe a que tanto la cerámica como los suelos contenían una amplia variabilidad de componentes, y el método de vinculación permitió identificar cuáles de dichos componentes determinaron que esas materias primas pudieran ser usadas como barro.

Se continuó con un método que nos permitió asociar proporciones de componentes similares de las mismas pastas: el método jerárquico aglomerativo del vecino más lejano, que nos dio la posibilidad de observar la proximidad entre dos grupos calculando la distancia entre sus objetos más lejanos o la similitud entre objetos que a simple vista eran menos semejantes o que parecían no tener vinculación. El método del vecino más lejano tiende a construir conglomerados pequeños y compactos y es útil para detectar valores atípicos (de la Fuente, sin año). A su vez, se extendió la muestra a través de la distancia euclidiana al cuadrado, que reduce con mucho el error estándar de la variabilidad de nuestra información.

El proceso estadístico se desarrolló en el programa estadístico MINITAB versión 14 (C) 1972-2003 Minitab Inc.), que fue utilizado para procesar los datos y generar los dendogramas. Los grupos fueron generados con una confiabilidad del 95\%.

\section{Resultados del análisis petrográfico: Definición de familias y patrones de pastas}

Las observaciones bajo microscopio petrográfico demostraron que todos los fragmentos de cerámica tienen la distribución relativa de los componentes finos y gruesos tipo porfírico cerrado (close porfiric cf. related distribution) (Stoops 2003). Eso significa que los granos gruesos de tamaño arena están inmersos en la matriz que separa las partículas arenosas, sin embargo, la distancia entre esas partículas es relativamente pequeña. La composición mineralógica de los componentes gruesos fue la base para la definir las familias de pastas. De esta manera se generaron un total de cinco familias de pastas:

Familia 1: Conformada por pastas que contienen un conjunto de minerales típico para las tefras andesíticas: vidrio volcánico identificado por sus formas típicas y ausencia de colores de interferencia bajo nícoles cruzados (vidrio volcánico negro y piedra pómez, o sea vidrio volcánico poroso), plagioclasas con su característico patrón laminar de birefrigencia definido por las maclas polisintéticas, 
Tabla 2. Relación y procedencia de muestras para elaboración de láminas delgadas.

\begin{tabular}{|c|c|c|c|c|c|}
\hline Clave & Temporada & Procedencia & Unidad estratigráfica & Descripción & Temporalidad \\
\hline PAC-1 & PEP-11 & Plaza Principal & 0 & Olla tipo Cañones & 5 \\
\hline PAC-2 & PEP-11 & Tecpan & 314 & Olla naranja pulido horizontal & 2 \\
\hline PAC-3 & PEP-11 & Estructura Sur & 184 & Olla gruesa alisada & 5 \\
\hline PAC-4 & PEP-11 & Tecpan & 287 & Olla baya pulido vertical & 1 \\
\hline PAC-5 & PEP-11 & Estructura Sur & 184 & Olla pasta burbujeante & 5 \\
\hline PAC-6 & PEP-11 & Tecpan & 176 & Olla tipo Cañones bayo & 5 \\
\hline PAC-7 & PEP-11 & Tecpan & 114 & Cuenco negro de pasta naranja & 4 \\
\hline PAC-8 & PEP-11 & Estructura Sur & 251 & Cajete tipo Coyotlatelco & 2 \\
\hline PAC-9 & PEP-11 & Tecpan & 233 & Cajete negro de silueta compuesta & 4 \\
\hline PEP-10 & PEP-11 & Tecpan & 136 & Cuenco negro pulido & 2 \\
\hline PEP-11 & PEP-11 & Tecpan & 114 & Sahumador & 4 \\
\hline PEP-12 & PEP-11 & Tecpan & 293 & Brasero & 2 \\
\hline PEP-13 & PEP-11 & Tecpan & 174 & Cajete tipo Rojo inciso postcocción Xajay & 5 \\
\hline PEP-14 & PEP-11 & Tecpan & 222 & Pipa & 2 \\
\hline PEP-15 & PEP-11 & Estructura Sur & 251 & Olla de pasta rosa & 2 \\
\hline PEP-16 & PEP-11 & Estructura Sur & 251 & Olla de pasta rosa con anfíboles & 2 \\
\hline PEP-17 & PEP-11 & Tecpan & 174 & Olla tipo Blanco levantado & 5 \\
\hline PEP-18 & PEP-11 & Tecpan & 237 & Cuenco con decoración al negativo & 2 \\
\hline PEP-19 & PEP-11 & Tecpan & 228 & Olla con engobe negro & 2 \\
\hline PEP-21 & PEP-11 & Tecpan & 152 & Olla con superficie porosa & 5 \\
\hline
\end{tabular}

anfíboles o piroxenos con colores de interferencia altos, fragmentos rocosos y óxidos de hierro (Figura 4).

Familia 2: Contiene vidrio volcánico (vidrio volcánico negro y piedra pómez), plagioclasas, anfíboles o piroxenos, fragmentos rocosos, óxidos de hierro y pápulas (fragmentos de los cutanes arcillosos) (Figura 5a).

Familia 3: Contiene calcitas con sus característicos colores de interferencia muy altos, óxidos de hierro y cuarzos policristalinos (Figura 5b).

Familia 4: Contiene fragmentos de esquisto, cuarzo, mica (tipo muscovita), granate y óxidos de hierro (Figura 5c).

Posteriormente las familias de pastas fueron subagrupadas por patrones de pastas bajo los métodos estadísticos mencionados en el apartado 3.5. Los criterios para elegir los componentes principales a partir de los cuales se agruparon los datos tomaron en cuenta la génesis de la cerámica. Es decir, como no fue utilizado ningún tipo de desgrasante y la variabilidad de los componentes está dado por la elección de distintos bancos, se eligieron los componentes diagnósticos mayoritarios: el vidrio volcánico, los feldespatos y la cantidad de matriz. Los resultados están basados en la información presentada en las tablas obtenidas a partir del conteo porcentual de los minerales (Tabla 4 y Tabla 5).

De acuerdo con el dendrograma obtenido (Figura 6a), se propone que la familia 1 agrupa siete patrones de pastas; el resto de los patrones fueron definidos de manera individual debido al número de casos presentados por familia (Tabla 6).

\subsection{RESULTADOS DEL ANÁLISIS MICROMORFOLÓGICO DE SUELOS}

El análisis micromorfológico permitió identificar algunos rasgos diagnósticos sobre la filiación edafológica de las muestras, así como su composición mineralógica:

1. Feozem: Si bien el suelo conocido como feozem no tiene como característica principal ser un suelo arcilloso, los procesos de iluviación pueden llegar a acumular minerales 
Tabla 3. Relación y localización de nuestros suelos.

\begin{tabular}{|c|c|c|}
\hline Clave & N (m) & E (m) \\
\hline M1-PEP & 429292 & 2265729 \\
\hline M2-PEP & 427278 & 2264319 \\
\hline M3-PEP & 428118 & 2266160 \\
\hline M4-PEP & 430600 & 2271700 \\
\hline M6-PEP & 431736 & 2260885 \\
\hline M10-PEP & 429917 & 2263673 \\
\hline
\end{tabular}

arcillosos en estos suelos como en el feozem desarrollado sobre estas mesas. De acuerdo con la caracterización mineralógica realizada a partir de los estudios micromorfológicos, el feozem de la región está conformado por minerales de origen volcánico como vidrio volcánico, plagioclasas, anfíboles o piroxenos y fragmentos rocosos. Las proporciones y tamaños de estos minerales varían de acuerdo con su localización, es decir, con los distintos horizontes edafológicos y distintas zonas dentro del área general de distribución del suelo (Figura 7a y 7b) (Tabla 7).

2. Luvisol: Según la analogía con la región cercana del norte de la Cuenca de México/ Valle de Teotihuacán, se trata de un paleosuelo desarrollado durante el Pleistoceno tardío, cuando las condiciones climáticas eran más húmedas (asociado probablemente a un ambiente boscoso) (Solleiro et al., 2006). Está conformado por minerales de origen volcánico y minerales arcillosos del tipo de las illitas y esmectitas que se presentan a manera de cutanes de iluviación. Los minerales identificados fueron vidrio volcánico, plagioclasas, anfíboles o piroxenos y fragmentos rocosos (Figura 8c y 8d) (Tabla $8)$.

3. Vertisol: Está conformado por una matriz de minerales arcillosos, principalmente esmectitas que, debido a dinámicas de expansión y contracción características de estos minerales, produce grietas donde se forman cutanes de estrés (Kovda y Mermut, 2010). Respecto a su composición mineralógica se detectaron pocos feldespatos y algunos fragmentos rocosos que cuantitativamente conforman menos del 1\% de los suelos (Figura 7e y $7 \mathrm{f}$ ).

\subsection{GORRELAGIÓN ENTRE EL ANÁLISIS PETROGRÁFICO Y MICROMORFOLÓGICO}

Se realizó el mismo procedimiento estadístico de clasificación usado para los patrones de pastas, tomando en cuenta únicamente las muestras cerámicas de la familia 1 (ya que son las que están correlacionadas con este tipo de suelo) y las tres muestras de feozem (Figura 6b).

Los resultados nos permiten afirmar que existe un $95 \%$ de probabilidad de que los bancos M10 y M2 hayan sido utilizados como fuente de materia prima para la elaboración de las cerámicas correspondientes a algunas de las muestras del patrón 6 (PAC-15, 21 y 9) y al patrón 5 (PAC-11 y 18), respectivamente. Por su parte la muestra M3 no corresponde cuantitativamente ( $95 \%$ de similitud) con las muestras de cerámica analizadas.

\subsection{EL ANÁLISIS DIAGRÓNICO}

Se realizaron tablas cruzadas para evaluar la persistencia en la explotación de las materias primas, así como de la explotación de los bancos identificados.

Puede observarse en la Tabla 9 que tanto los yacimientos de feozem como de luvisol, correspondientes a las familias 1 y 2 respectivamente, fueron explotados durante toda la ocupación del sitio. En el caso de la cerámica alcotana, la familia 3 no fue tomada en cuenta por el bajo número de datos, pero puede notarse que la familia 4 se encuentra presente durante toda la línea temporal.

Por su parte, los patrones de pasta usados con mayor frecuencia ( 1 y 6 ) se mantienen constantes durante la línea temporal (Tabla 10). El uso de los bancos correspondientes a los patrones 3 y 7 también permanece constante, pero fueron explotados en menor medida. En el caso del patrón de pasta 2, que corresponde a braseros y pipas, se observa un aumento en su producción y consumo durante 

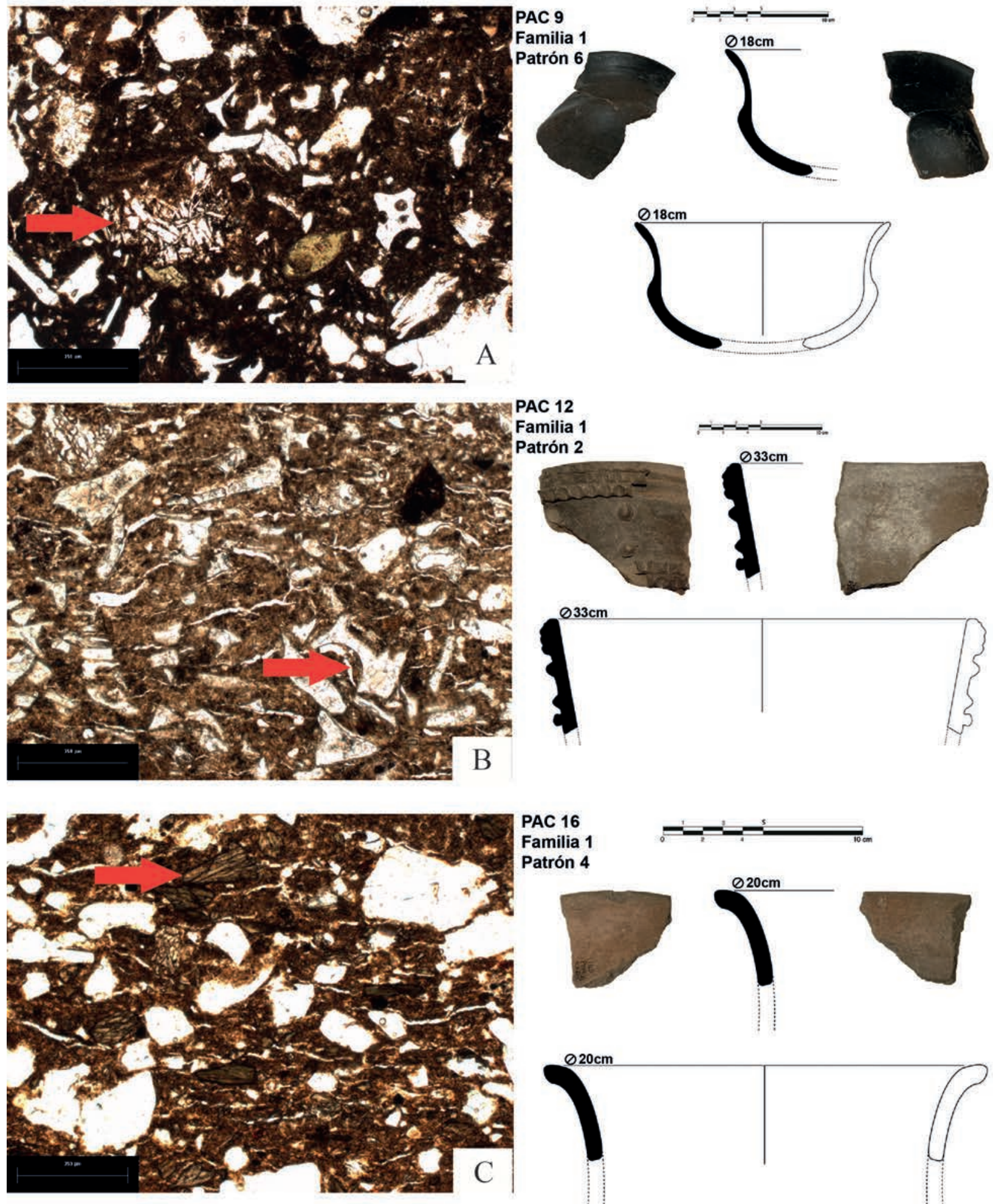

PAC 16

Familia 1

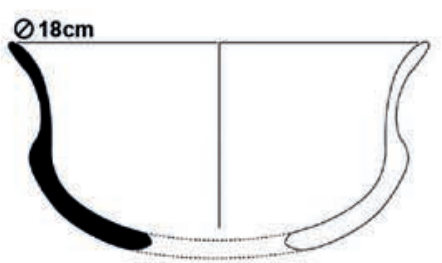

Patrón 4
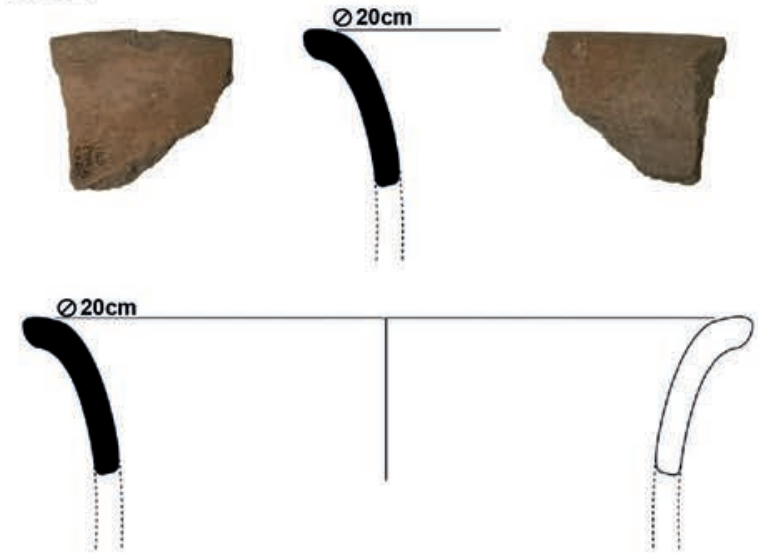

Figura 4 Imágenes del análisis petrográfico de muestras cerámicas y formas cerámicas, agrupadas dentro de la Familia 1, se señalan algunos componentes principales: fragmento rocoso (A) vidrio volcánico (B), anfíbol (C). A) Muestra PAC9 (luz paralela), Familia 1, Patrón 6, pertenece a un cuenco de silueta compuesta. B) Muestra PAC12 (luz paralela), Familia 1, Patrón 2, perteneciente a un brasero. C) Muestra PAC16 (luz paralela), Familia 1, Patrón 4, pertenece a una olla. 


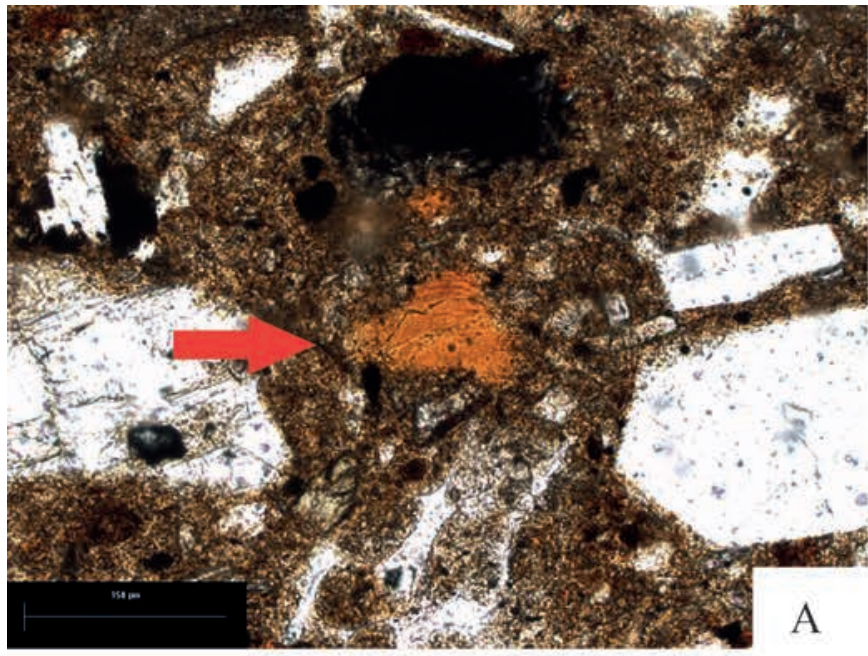

PAC 13

Familia 2

Patrón 1
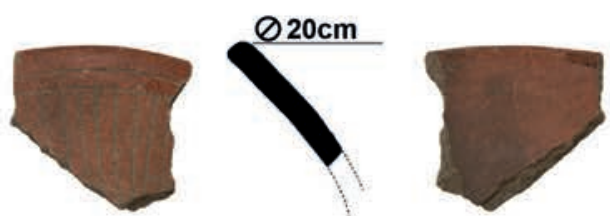

$020 \mathrm{~cm}$
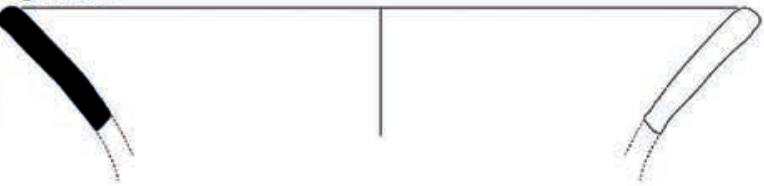

PAC 10

Familia 3

Patrón 2

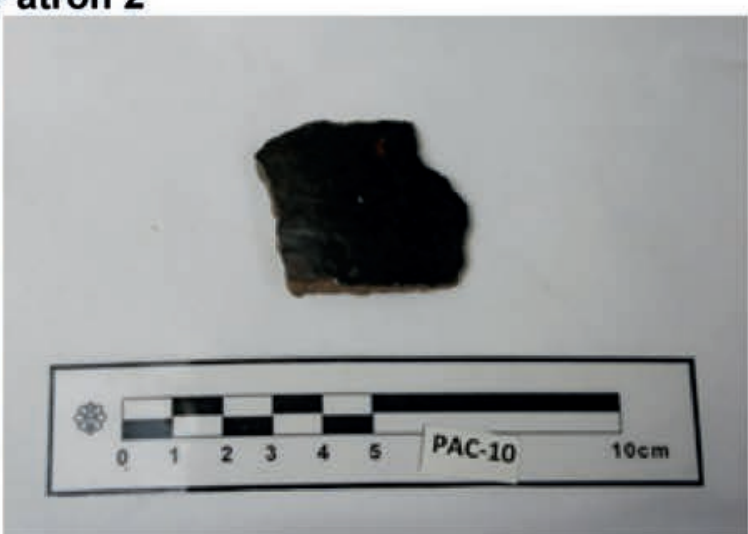

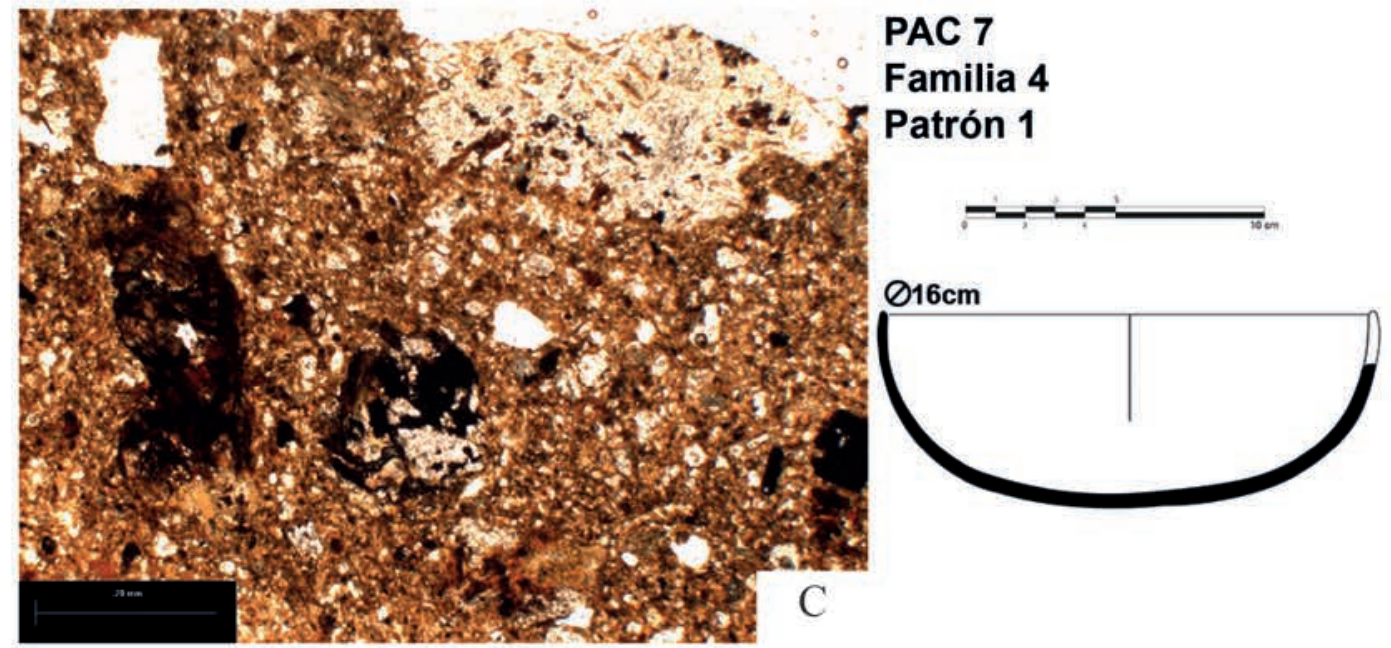

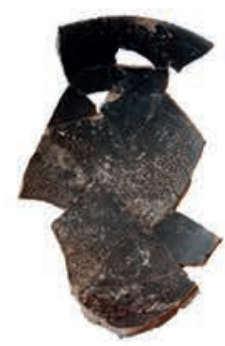

Figura 5 Imágenes del análisis petrográfico de muestras cerámicas y formas cerámicas. A) Muestra PAC13 (luz paralela), Familia 2 , Patrón 1, nótese la presencia de pápulas, pertenece a un cajete tipo Rojo Inciso Post-cocción Xajay. B) PAC10 (luz paralela), Familia 3 , Patrón 2, contiene calcitas, pertenece a un cuenco negro pulido. C) PAC7 (luz paralela) Familia 4, Patrón 1, pertenece a un cuenco. 
Tabla 4. Análisis cuantitativo a partir de porcentajes de fases minerales a partir de comparación con plantillas gráficas.

\begin{tabular}{|c|c|c|c|c|c|c|}
\hline Clave & Familia & $\%$ Plagioclasa & $\begin{array}{l}\text { \%Vidrio } \\
\text { volcánico }\end{array}$ & $\begin{array}{c}\% \text { Anfíbol o } \\
\text { piroxeno }\end{array}$ & $\begin{array}{l}\text { \% Frag. } \\
\text { Rocosos }\end{array}$ & $\%$ Cuarzo \\
\hline PAC-1 & 1 & 8 & 41 & 2 & 1 & 0 \\
\hline PAC-2 & 1 & 10 & 45 & 2 & 1 & 0 \\
\hline PAC-3 & 1 & 30 & 3 & 2 & 2.5 & 0 \\
\hline PAC-4 & 1 & 10 & 33 & 2 & 2 & 0 \\
\hline PAC-5 & 3 & 0 & 0 & 0 & 0 & 0 \\
\hline PAC-6 & 1 & 10 & 31 & 1 & 1 & 1 \\
\hline PAC-7 & 4 & 0 & 0 & 0 & 0 & 15 \\
\hline PAC-8 & 1 & 30 & 0.5 & 2 & 1 & 0 \\
\hline PAC-9 & 1 & 10 & 26 & 1 & 2 & 0 \\
\hline PAC-10 & 3 & 0 & 0 & 0 & 0 & 0 \\
\hline PAC-11 & 1 & 10 & 5 & 2 & 1 & 0 \\
\hline PAC-12 & 1 & 6 & 19.5 & 1 & 1 & 0 \\
\hline PAC-13 & 2 & 8 & 26.5 & 1 & 2 & 0 \\
\hline PAC-14 & 1 & 6 & 21 & 2 & 1 & 0 \\
\hline PAC-15 & 1 & 10 & 22 & 5 & 3 & 0 \\
\hline PAC-16 & 1 & 15 & 1 & 12.5 & 1 & 0 \\
\hline PAC-17 & 1 & 20 & 0.5 & 3 & 1 & 0 \\
\hline PAC-18 & 1 & 6 & 11 & 2 & 1 & 0 \\
\hline PAC-19 & 1 & 7 & 30 & 3 & 1 & 0 \\
\hline PAC-20 & 1 & 8 & 30 & 2 & 1 & 0 \\
\hline PAC-21 & 1 & 8 & 25 & 5 & 1 & 0 \\
\hline
\end{tabular}

el momento de ampliación del Epiclásico (temporalidad 3), aunque esta idea deberá corroborarse una vez que se amplíe el número de muestras en estudios futuros.

\section{Discusión de resultados}

A partir de los resultados obtenidos se propone que hubo al menos dos suelos que fueron utilizados como materia prima para la elaboración del barro: el feozem utilizado para la fabricación de la mayoría de los objetos, y el luvisol, destinado a la producción de un solo tipo de objeto, tipológicamente conocido como cajetes "Rojo inciso postcocción Xajay" (Nalda, 1975) (Figura 5a).
Respecto a la preparación del barro fue posible determinar que no fue utilizado ningún tipo de desgrasante (agregado cultural) para la preparación de las pastas. Las diferencias porcentuales del material antiplástico cuantificado se deben a la elección de distintos bancos en una misma formación de suelo.

Para intentar comprender cuales fueron los criterios de selección de los distintos bancos identificados, se realizó una prueba de correlación estadística. El objetivo fue reconocer si existe una relación entre las proporciones de los componentes minerales de la cerámica y del suelo. El análisis muestra que existe una correlación negativa y significativa entre la matriz y el vidrio volcánico, así como entre la cantidad de feldespatos y de vidrio volcánico (Tabla 11). Esta correlación puede re- 
Tabla 5. Continuación de resultados del análisis cualitativo a partir de gráfico para estimación visual de porcentajes.

\begin{tabular}{|c|c|c|c|c|c|c|}
\hline Clave & $\begin{array}{c}\% \text { Cuarzo } \\
\text { policristalino }\end{array}$ & $\begin{array}{c}\% \text { Calcita } \\
\text { de esquisto }\end{array}$ & $\begin{array}{c}\text { \% Mica- } \\
\text { muscovita }\end{array}$ & \% Granate & Matriz \\
\hline PAC-1 & 0 & 0 & 0 & 0 & 0 & 47 \\
\hline PAC-2 & 0 & 0 & 0 & 0 & 0 & 41 \\
\hline PAC-3 & 0 & 0 & 0 & 0 & 0 & 61.5 \\
\hline PAC-4 & 0 & 0 & 0 & 0 & 0 & 52 \\
\hline PAC-5 & 2 & 10 & 0 & 0 & 0 & 85 \\
\hline PAC-6 & 0 & 0 & 0 & 0 & 0 & 55 \\
\hline PAC-7 & 0 & 0 & 30 & 7 & 1 & 47 \\
\hline PAC-8 & 0 & 0 & 0 & 0 & 0 & 64.5 \\
\hline PAC-9 & 0 & 0 & 0 & 0 & 0 & 60 \\
\hline PAC-10 & 7 & 15 & 0 & 0 & 0 & 75 \\
\hline PAC-11 & 0 & 0 & 0 & 0 & 0 & 81 \\
\hline PAC-12 & 0 & 0 & 0 & 0 & 0 & 71.5 \\
\hline PAC-13 & 0 & 0 & 0 & 0 & 0 & 61.5 \\
\hline PAC-14 & 0 & 0 & 0 & 0 & 0 & 69 \\
\hline PAC-15 & 0 & 0 & 0 & 0 & 0 & 59 \\
\hline PAC-17 & 0 & 0 & 0 & 0 & 0 & 69.5 \\
\hline PAC-18 & 0 & 0 & 0 & 0 & 0 & 84 \\
\hline PAC-19 & 0 & 0 & 0 & 0 & 0 & 79 \\
\hline PAC-20 & 0 & 0 & 0 & 0 & 0 & 58 \\
\hline PAC-21 & 0 & 0 & 0 & 0 & 0 & 58 \\
\hline
\end{tabular}

presentarse a partir de un diagrama de dispersión (Figura 8) en el que se observa que los datos tienen una tendencia lineal con pendiente negativa, lo cual indica que, a mayor cantidad de vidrio volcánico, menor cantidad de matriz.

De acuerdo con las muestras analizadas, la mayoría de las ollas tiene una composición mineralógica en la que predomina el vidrio volcánico. Algunas ollas fueron elaboradas con materiales procedentes de otros bancos. Esto puede observarse especialmente en la muestra PAC-3 que corresponde a un tipo de ollas (las de mayores dimensiones en el sitio) que contiene únicamente un $1 \%$ de vidrio volcánico. Esta prueba sugiere que cada tipo de objeto era producido a partir de un banco de material específico y que la elección de los bancos no fue aleatoria.

Asimismo, se determinó que la mayoría de la cerámica consumida en Pahñu es de origen local. Las muestras pertenecientes a las familias 1 y 2 contienen componentes mineralógicos que pueden localizarse en los suelos generados en el sustrato geológico volcánico de la región.

La cerámica agrupada dentro de la familia 1 fue elaborada con feozem. Esta hipótesis se sustenta en que los componentes mineralógicos, sus formas y tamaños corresponden con los identificados en este suelo (compárense Figuras 7a y 7b con Figura 4).

Dentro de esta familia se puede inferir que los patrones de pasta 3 y 17, que se caracterizan por tener un contenido de vidrio volcánico de apenas un $5 \%$, pudieron haber sido extraídos de horizontes edafológicos más profundos (véase Tabla 4).

La cerámica agrupada dentro de la familia 2 fue elaborada con luvisol. Aunque las familias 1 y 2 contienen los mismos componentes antiplásticos, el luvisol es un suelo que se caracteriza por formar 
Dendograma de agrupación por patrones con el método del vecino lejano y distancia euclidiana al cuadrado
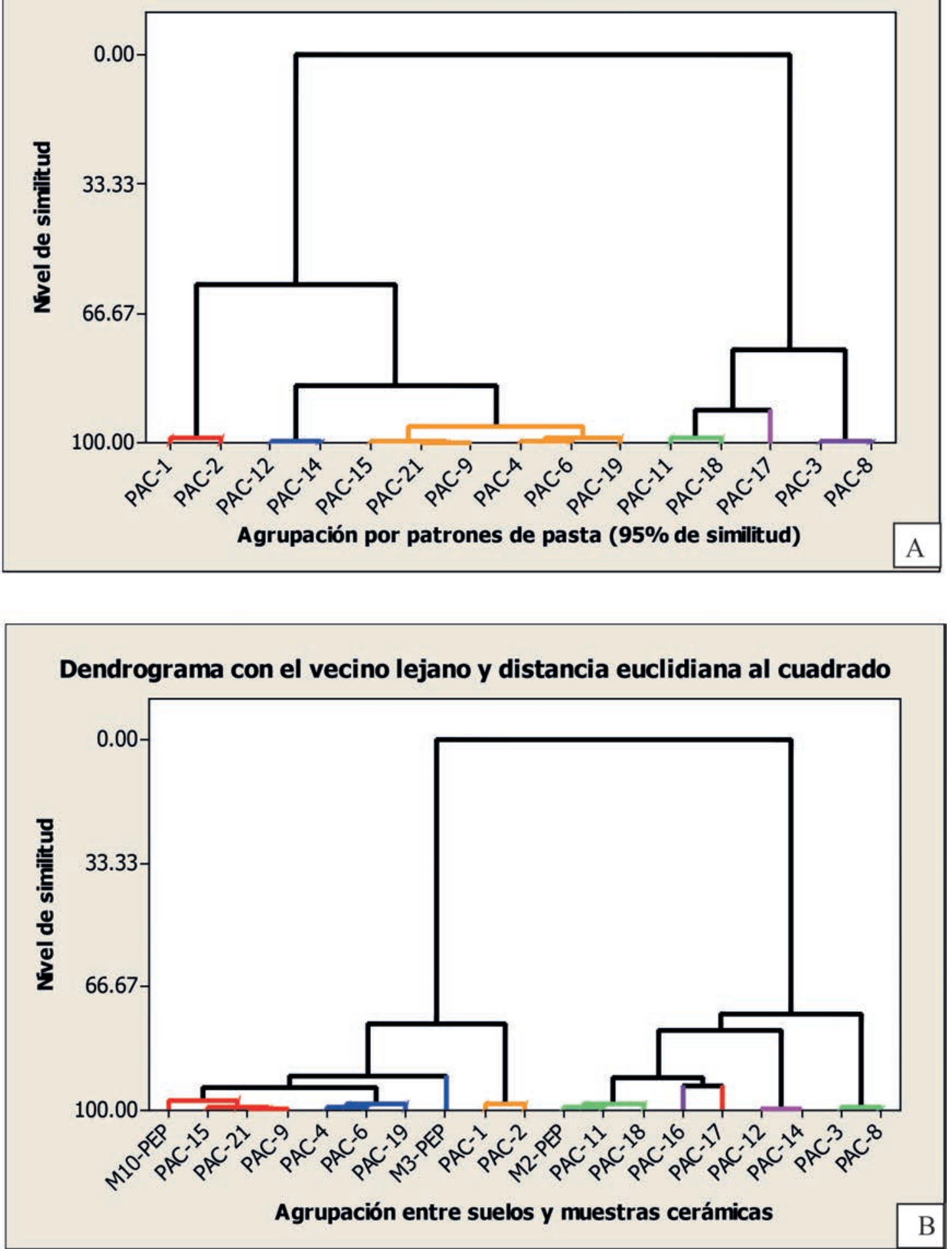

Figura 6 A) Dendrograma que presenta la agrupación de muestras cerámicas de la familia 1 por patrones de pastas. B) Dendrograma que presenta la correlación entre muestras cerámicas de la familia 1, y muestras de suelos de Feozem. 
Tabla 6. Agrupación de muestras por familias y patrones de pastas.

\begin{tabular}{|c|c|c|c|}
\hline Familias & Patrones & Clave de muestra & Descripción \\
\hline \multirow{16}{*}{ Familia 1} & \multirow{2}{*}{ F1 P1 } & PAC-1 & Olla tipo cañones (grueso) \\
\hline & & PAC-2 & Olla naranja con pulido horizontal \\
\hline & \multirow{2}{*}{ F1P2 } & PAC-14 & Pipa \\
\hline & & PAC-12 & Brasero \\
\hline & F1 P3 & PAC-3 & Olla gruesa alisada \\
\hline & F1 P4 & PAC-16 & Olla de pasta rosa con anfíboles \\
\hline & \multirow{2}{*}{ F1 P5 } & PAC-11 & Sahumador \\
\hline & & PAC-18 & Negativo \\
\hline & \multirow{6}{*}{ F1 P6 } & PAC-4 & Olla baya con pulido vertical \\
\hline & & PAC-6 & Olla tipo cañones bayo \\
\hline & & PAC-19 & Olla pulida con engobe negro \\
\hline & & PAC-9 & Cajete negro pulido de silueta compuesta \\
\hline & & PAC-15 & Olla pasta rosa \\
\hline & & PAC- 21 & Olla pulida con poros \\
\hline & F1P7 & PAC-8 & Coyotlatelco \\
\hline & F1 P8 & PAC-17 & Blanco levantado \\
\hline Familia 2 & F2 P1 & PAC-13 & Cajete Rojo inciso post-cocción Xajay \\
\hline \multirow{2}{*}{ Familia 3} & F3 P1 & PAC-5 & Olla de pasta con burbujas \\
\hline & F3 P2 & PAC-10 & Cuenco negro pulido \\
\hline Familia 4 & F4 P1 & PAC-7 & Cuenco negro de pasta naranja \\
\hline
\end{tabular}

cutanes arcillosos, denominados pápulas cuando se localizan al interior de una muestra cerámica, que difícilmente pueden ser desintegrados en su totalidad a través de su pulverización y que por esta razón pueden ser considerados como un rasgo diagnóstico de este tipo de suelo (Cabadas et al., 2017) (Figura 5a, 7c y 7d).

Las familias de origen alóctono corresponden a las 3 y 4 . La familia 3 arrojó un contenido mineralógico conformado de calcita y cuarzos policristalinos que, si bien podrían provenir de las formaciones sedimentarias localizadas a menos de $5 \mathrm{~km}$ de los sitios Xajay, la ausencia de minerales de origen volcánico en su contenido (vidrio volcánico, feldespatos, plagioclasas y anfíboles) nos permite suponer esto, ya que los suelos de la región aparentemente siempre contienen (en mayor o menor proporción) minerales volcánicos (Figura 5b).

La familia 4 contiene componentes de origen metamórfico que, en definitiva, no están presentes en la región (Figura 5c).

Si bien los vertisoles son los suelos que de manera natural podrían considerarse como aquellos mayormente aptos para ser usados como barro, éstos no fueron elegidos como materia prima. Esto puede deberse a que en el universo de posibilidades existentes en el medio del grupo Xajay, este grupo optó por explotar suelos que ya contenían material antiplástico, ya que el usar el vertisol hubiera implicado una mayor inversión de tiempo en 

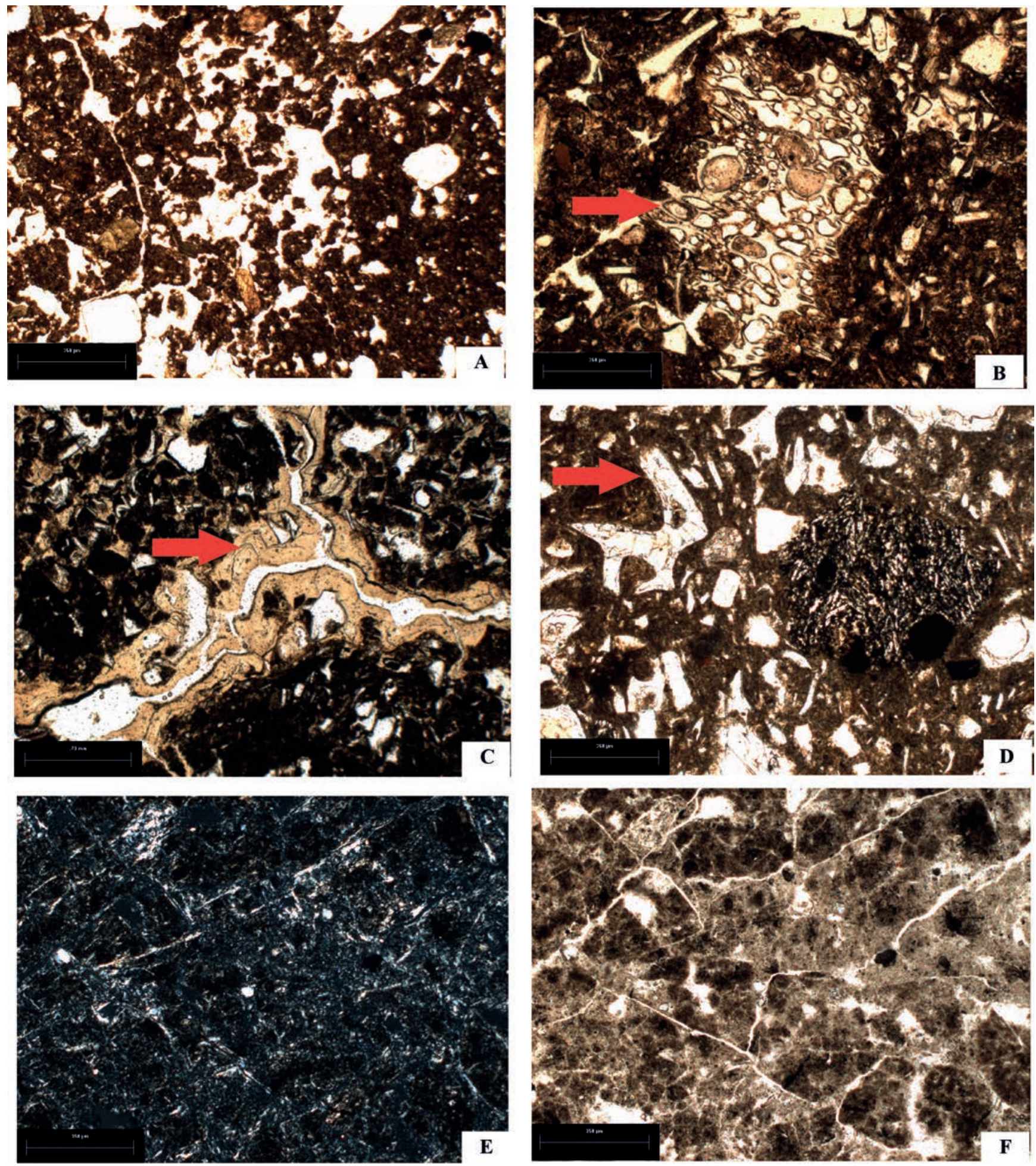

Figura 7 Muestras de suelos. A) Feozem (M2, luz paralela), vista general. B) Feozem (M3, luz paralela), partícula de vidrio volcánico. C) Luvisol (M1, luz paralela), véanse cutanes de arcilla. D) Luvisol (M1, luz paralela), véase presencia de vidrio volcánico. E) Vertisol (M4, nícoles cruzados). F) Vertisol (M4, luz paralela). 
Tabla 7. Análisis cualitativo de muestras identificadas como Feozem.

\begin{tabular}{|c|c|c|c|c|c|}
\hline Clave & \% Plagioclasas & $\begin{array}{c}\text { \% Vidrio } \\
\text { volcánico }\end{array}$ & $\begin{array}{c}\text { \% Anfíboles o } \\
\text { piroxenos }\end{array}$ & \% Frag. Rocosos & \% Matriz \\
\hline M10-PEP & 15 & 20 & 6 & 2 & 57 \\
\hline M2-PEP & 8 & 5 & 7 & 2 & 78 \\
\hline M3-PEP & 20 & 25 & 7 & 2 & 46 \\
\hline
\end{tabular}

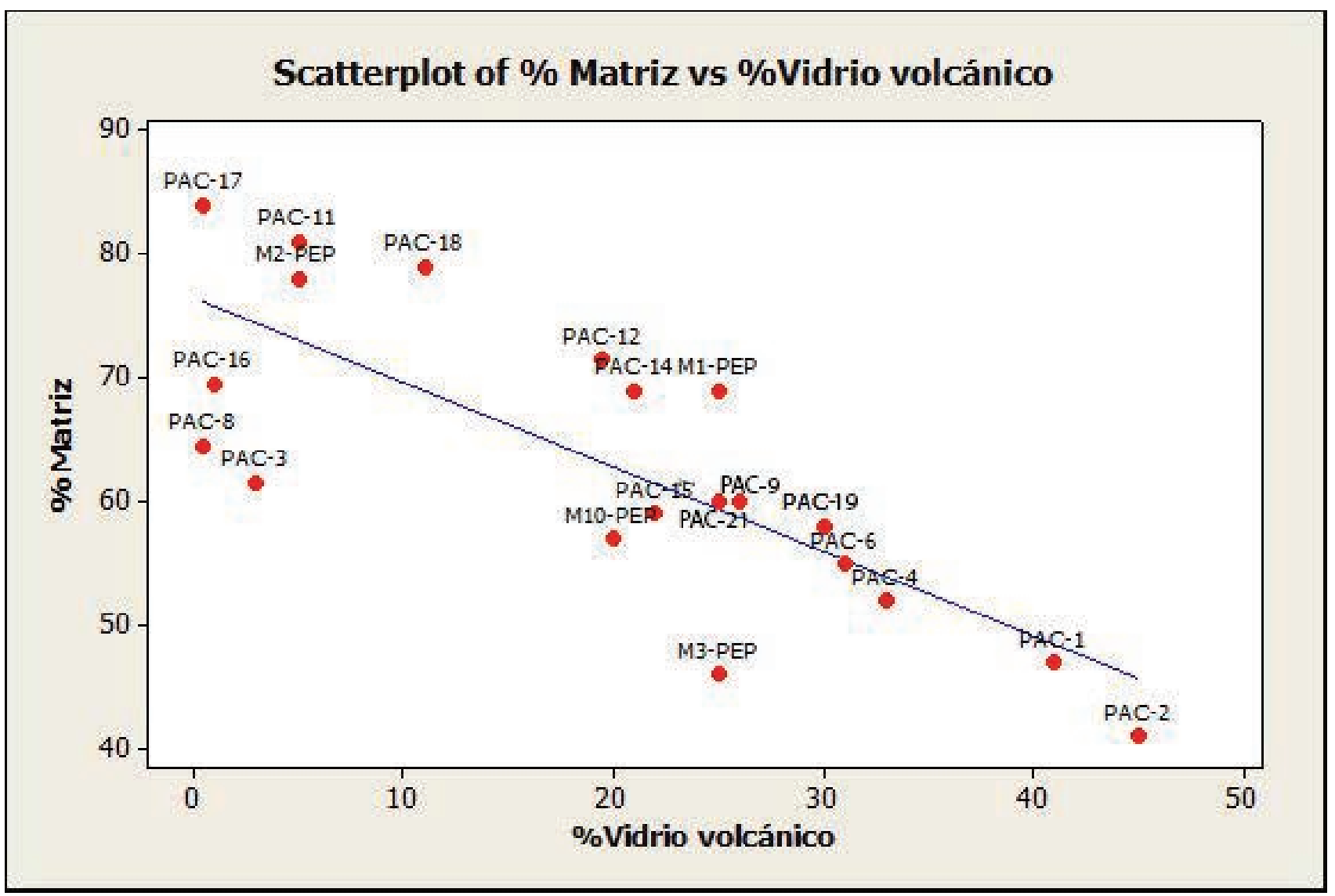

Figura 8 Diagrama de dispersión que representa la correlación entre vidrio volcánico y matriz, en las muestras cerámicas de las Familias 1 y 2 y muestras de suelo feozem y luvisol. La línea corresponde a la recta de regresión lineal.

Tabla 8. Análisis cualitativo de muestras identificadas como luvisol.

(⿸丆口


Tabla 9. Tabla cruzada que muestra la continuidad, durante las 5 etapas del sitio, en la explotación de mismos tipos de suelo (familias).

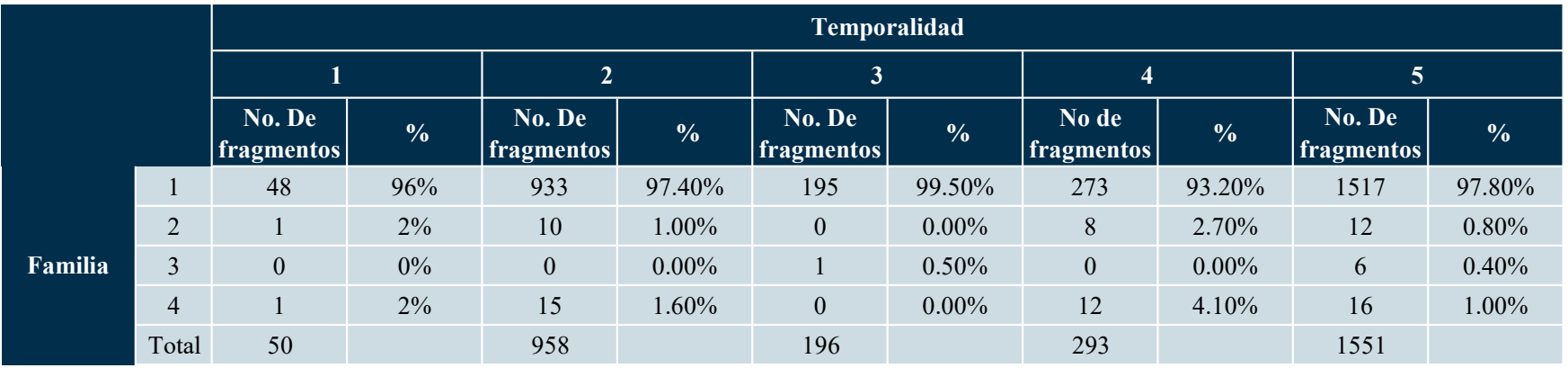

Tabla 10. Tabla cruzada que evalúa la persistencia de la explotación de bancos específicos (patrones) dentro del mismo tipo de suelo (familia), durante las 5 etapas del sitio.

\begin{tabular}{|c|c|c|c|c|c|c|c|c|c|c|c|}
\hline \multirow[b]{3}{*}{ Familia } & \multirow[b]{3}{*}{ Patrón } & \multicolumn{10}{|c|}{ Temporalidad } \\
\hline & & \multicolumn{2}{|c|}{1} & \multicolumn{2}{|c|}{2} & \multicolumn{2}{|c|}{3} & \multicolumn{2}{|c|}{4} & \multicolumn{2}{|c|}{5} \\
\hline & & No. Frag. & $\%$ & No. Frag. & $\%$ & No. Frag. & $\%$ & No. Frag. & $\%$ & No. Frag. & $\%$ \\
\hline \multirow{7}{*}{1} & 1 & 22 & 45.8 & 408 & 43.7 & 55 & 28.2 & 67 & 24.5 & 487 & 32.1 \\
\hline & 2 & 2 & 4.2 & 61 & 6.5 & 80 & 41 & 22 & 8.1 & 398 & 26.2 \\
\hline & 3 & 0 & 0 & 117 & 12.5 & 20 & 10.3 & 43 & 15.8 & 250 & 16.5 \\
\hline & 4 & 1 & 2.1 & 1 & 0.1 & 0 & 0 & 0 & 0 & 7 & 0.5 \\
\hline & 5 & 7 & 14.6 & 62 & 6.6 & 1 & 0.5 & 38 & 13.9 & 51 & 3.4 \\
\hline & 6 & 16 & 33 & 272 & 29.2 & 38 & 19.5 & 99 & 36.3 & 311 & 20.5 \\
\hline & 7 & 0 & 0 & 12 & 1.3 & 1 & 0.5 & 4 & 1.5 & 13 & 0.9 \\
\hline 2 & 1 & 1 & 100 & 10 & 100 & 0 & 0 & 8 & 100 & 12 & 100 \\
\hline 3 & 1 & 0 & 0 & 0 & 0 & 1 & 100 & 0 & 0 & 6 & 100 \\
\hline \multirow[t]{2}{*}{4} & 1 & 1 & 100 & 15 & 100 & 0 & 0 & 12 & 100 & 16 & 100 \\
\hline & Total & 50 & & 958 & & 196 & & 293 & & 1551 & \\
\hline
\end{tabular}

Tabla 11. Prueba de correlación estadística. Se muestran los valores p de los coeficientes de correlación, para evaluar si la correlación entre las variables es significativa o no. Los marcados en gris son los valores p que indican una correlación estadísticamente significativa (menor o igual a .05)

\begin{tabular}{|c|c|c|c|c|c|}
\hline & Plagioclasas & Vidrio volcánico & Anfíboles & Frag. Rocosos & Matriz \\
\hline Plagioclasas & 1 & & & \\
\hline Vidrio volcánico & -0.5094 & & & & \\
\hline & $\mathbf{0 . 0 2 1 8}$ & & & & \\
\hline Anfíboles & 0.1227 & -0.3301 & 1 & & \\
\hline Frag. Rocosos & 0.6063 & 0.1552 & & & \\
\hline & 0.2757 & -0.0491 & 0.1874 & & \\
\hline Matriz & 0.2394 & 0.8371 & 0.4289 & & \\
\hline & 0.7831 & -0.7849 & 0.0609 & -0.2286 & 1 \\
\hline
\end{tabular}


la preparación de las pastas; la distancia para su obtención no pudo haber sido un factor discriminante para el grupo debido a que estos suelos se localizan en zonas próximas a los sitios.

Finalmente, los análisis temporales sugieren que las prácticas ligadas tanto a la elección y explotación de materias primas como a su preparación permanecieron constantes durante la ocupación del sitio.

\section{Conclusiones}

El grupo Xajay habitó una zona que los proveía de las materias primas necesarias para poder producir objetos cerámicos. Dentro de los distintos tipos de suelos existentes en la región - vertisol, luvisol y feozem - ellos optaron por la utilización de los últimos dos.

El uso mayoritario de feozem para la producción de la cerámica, así como la localización de los bancos de material en los alrededores de los sitios, nos hacen pensar que los recursos eran abundantes y de libre acceso. Únicamente la producción de los cajetes Rojo inciso post-cocción Xajay, elaborados con luvisol, al parecer estuvo relacionada con un área de extracción de materiales más restringida. Los análisis micromorfológicos caracterizaron a este suelo como un paleosuelo; probablemente éste no estaba expuesto en el momento de ocupación y debían remover primero el feozem que lo cubría para extraerlo.

Asimismo, la explotación regular de estos bancos al menos durante el tiempo en que el centro ceremonial Pahñu estuvo en uso, nos habla sobre la abundancia de las materias primas y de una misma forma de organización de la producción probablemente doméstica.

El sector del grupo Xajay que tenía a su cargo la extracción del barro elegía los bancos a partir de criterios que tenían que ver con su textura y granulometría, es decir, barros más gruesos vs. barros más finos o delgados. Aunque no hay una asociación clara entre el tipo de banco usado con la función, forma o técnica de manufactura, probablemente sí existía una selección de bancos en relación con ciertas formas cerámicas. Esta hipótesis se sustenta en que la variabilidad de pastas por formas se mantiene constante en la línea del tiempo. Es decir, aunque un mismo banco haya sido usando para fabricar diversas formas, esos mismos bancos fueron elegidos para realizar las mismas formas todo el tiempo de la ocupación.

Por su parte, el proceso de preparación de la pasta implicaba sólo la remoción de las partículas antiplásticas de mayor tamaño, como fragmentos rocosos que no eran muy abundantes, y no se agregaba ningún tipo de desgrasante.

La cerámica proviene de una producción mayoritariamente local. Por su parte, la identificación de la procedencia de los materiales exógenos aún no ha sido estudiada.

Los resultados expuestos en torno a las dos primeras etapas de producción, sumados al resto del proceso, evidenciaron una cadena operatoria que fue transmitida de generación en generación durante la vida del sitio Pahñu. La perennidad en la elección y transformación de las materias primas, aunada a la continuidad en el uso de las técnicas de manufactura (Castañeda, 2015), que constituye la variable de mayor importancia para argumentar la existencia de una tradición tecnológica (Roux, 2016; Gosselain, 2000), nos permiten argumentar la existencia de una tradición alfarera que representa también un elemento constitutivo de la identidad Xajay.

\section{Agradecimientos}

Gracias al CONACYT por haber financiado, a través de una beca de maestría, el presente proyecto de investigación. Al Proyecto Especial Pahñu, por haber proporcionado los medios para realizar el trabajo de campo y análisis de materiales. Al Instituto de Geología de la UNAM, por el apoyo en la realización de las láminas delgadas y su interpretación. Finalmente, a la Escuela Nacional de 
Antropología e Historia, especialmente al laboratorio de suelos y sedimentos por haber proporcionado la asesoría y los instrumentos necesarios para la elaboración del análisis petrográfico.

\section{Referencias}

Avilez-Moreno, M.R., Solar-Valverde, L., 2006, Constantes y variables en el complejo cerámico de las moras, un sitio Epiclásico en el norte del Estado de México, en SolarValverde, L. (ed.), El fenómeno Coyotlatelco en el centro de México: Tiempo, espacio y significado. Memoria del primer SeminarioTaller sobre problemáticas regionales, INAH, México, 163-181.

Bonfil-Olvera, A., 2006, La cerámica rojo sobre bayo y el complejo San Juan. Primeros acercamientos al epiclásico del norte del Estado de México, en Solar-Valverde, L. (ed.), El fenómeno Coyotlatelco en el centro de México: Tiempo, espacio y significado. Memoria del primer Seminario-Taller sobre problemáticas regionales, INAH, México, 291-308.

Cabadas-Báez, H., Sedov, S., Jiménez-Álvarez, S., Leonard, D., Lailson-Tinoco, B., GarcíaMoll, R., Ancona-Aragón, I., HernándezVelázquez, M., 2017, Soils as a Source of Raw Materials for Ancient Ceramic production in the Maya region: Micromorphological insight: Boletín de la Sociedad Geológica Mexicana, 70(1), 21-48.

Castañeda, A., 2015, La cerámica Xajay: Una aproximación tecnológica y cognitiva a través de cadenas operatorias, México, Escuela Nacional de Antropología e Historia, Tesis de Maestría en Arqueología, 375 p.

Cedeño, J., 1998, El culto al lugar central. Posibilidades en torno a un problema arqueológico: Arqueología, Segunda Época, 20, 53-64.
Cervantes Rosado, J. y Fournier García, P., 1994, Regionalización y Consumo: Una aproximación a los complejos cerámicos epiclásicos del Valle del Mezquital, México: Boletín de Antropología Americana, 29, 105-130.

Chaves-Alves, A.G., 2005, Conhecimento local e uso do solo: uma abordagem etnopedológica, Interciencia, 30(9), 524-528.

Chaves-Alves, A.G., Wanderley-Marques, J.G., Barreto de Queiroz, S., da Silva, I., RosasRibeiro, M., 2005, Seção V-Gênese, Morfologia e Classificação do solo. Caracterização etnopedológica de planos solos utilizados em cerâmica artesanal no agreste paraibano, Separata: Revista Brasileira de Ciências do Solo, 29(3), 379-388.

Cortés, A., Lozano, A., Pérez, J., Quezadas, J., Martínez, F., 2006, Estudio exploratorio de las condiciones isotópicas e hidrogeoquímicas de afloramientos en la comunidad de El Arbolito, Municipio de Cadereyta, Qro. Centro Queretano de Recursos Naturales, Reporte Técnico, Tomo X, México, 35 p.

Crespo-Oviedo, A.M., Saint-Charles, J.C., 1996, Ritos Funerarios y Ofrendas de Élite. Las Vasijas Xajay, en Crespo, A.M. y Viramontes, C. (coords.), Tiempo y Territorio en Arqueología, El Centro-Norte de México, Colección Científica del INAH, México, 323, 115-142.

Creswell, R., 1973, Techniques et culture: les bases d'un programme de travail: Techniques et culture, 1, 7-59.

De la Fuente, L., sin año, Análisis Cluster, (en línea), disponible en <http://www.estadistica. net/Master-Econometria/Analisis_Cluster. pdf>, consultado 9 de abril 2018.

De la Vega-Doria, S., 2006, La alfarería en Los Reyes Metzontla: pasado presente y futuro, México, GONAGULTA-INAH, Escuela 
Nacional de Antropología e Historia, CONACYT, Instituto Nacional de las Mujeres, $191 \mathrm{p}$.

De la Vega-Doria, S., 2007, La mujer alfarera ante la conservación del patrimonio, la economía social y familiar, México, INAH-ENAH, 136 p.

Farías, S., 2010, Identificación de la cultura de las mesas o Xajay, México, Escuela Nacional de Antropología e Historia, Tesis de Maestría, $68 \mathrm{p}$.

Farías, S., 2017, Characterization of cultural traits by means of fractal analysis, en Brambila, $\mathrm{F}$. (ed.), Fractal analysis. Aplications in health sciences and social sciences, INTECH, 167-183

Farías, S., Castañeda, A., 2014, La cultura Xajay: Desarrollo y territorio, en López, F., López, H. (eds.), Huichapan tres momentos de su historia: México, Consejo Estatal para la Cultura y las Artes, 23-35.

Gosselain, O.P., 2000, Materializing identities: an African perspective: Journal of Archaeological Method and Theory, 7(3), 187-217.

Guerrero, S., 2014, Tecnología cerámica de tradición indígena en lozas vidriadas en México durante los periodos Colonial y Republicano, México, Escuela Nacional de Antropología e Historia, Tesis de Maestría en Arqueología, 257 p.

Kovda, I., Mermut, A., 2010, Vertic features, en Stoops, G., Marcelino, V., Mees, F. (eds.), Interpretation of Micromorphological Features of Soils and Regoliths: Amsterdan, Elsevier, 109-137.

Lemonnier, P., 1992, Elements for an Anthropology of Technology, Michigan, Ann Arbor, 129 p.

Leroi-Gourhan, A., 1971, El gesto y la palabra, Caracas, Publicaciones de la Universidad Central de Venezuela, 394 p.

López, F., Solar, L., Vilanova, R., 1998, El Valle del Mezquital. Encrucijadas en la Historia de los Asentamientos Humanos: Arqueología, 20, 21-40.
López, F., Sandoval, G., Farías, S., 2012, Proyecto Especial Pahñu. Guía para el viajero. Zona arqueológica del Pahñu, Hidalgo, México, Instituto Nacional de Antropología e Historia, 16 p.

Milán, M., Yáñez, C., Navarro, I., Verma, S.P., Carrasco-Núñez, G., 1993, Geología y geoquímica de elementos mayores de la Caldera de Huichapan, Hidalgo, México: Geofisica Internacional, 32(2), 261-276.

MINITAB 14, 2003, Minitab Statistical Software (Web): State College, Pennsylvania, EE.UU, Minitab Inc., disponible en (http://www. minitab.com/es-mx/company/).

Mireles, C., 2015, Las tradiciones tecnológicas de la lítica tallada Xajay, Tesis de licenciatura, Universidad de Guadalajara, 212 p.

Morett-Alatorre, L., 1996, El desarrollo regional Xajay en el poniente del valle del Mezquital, México, II Coloquio de Historia Regional: Pachuca, Hidalgo. Archivo Técnico de Prehispánicos, México, INAH, 13 p.

Nalda, E., 1975, UA San Juan del Río. Trabajos Arqueológicos Preliminares, Escuela Nacional de Antropología e Historia, México, Tesis de Maestría, 139 p.

Nalda, E., 1991, Secuencia cerámica del sur de Querétaro, en Crespo, A.M., Brambila, R. (eds.), Querétaro Prehispánico, Colección Científica, México, Instituto Nacional de Antropología e Historia, 238, 31-56.

Perlès, C., 1987, Les industries lithiques taillés de Franchthi, Argolide: présentation générale et industries paléolithiques, Indiana University Press, 339 p.

Ramos-Galicia, Y., Hidalgo-Moreno, G., Sergey S., Poetsch, T., 2003, Comales of Tzompantepec and paleosols: a case study: Revista Mexicana de Ciencias Geológicas, 20(3), 263-269.

Roux, V., 2016, Des céramqiues et des homes: Décoder les assemblages archéologiques, Presses Universitaires de Paris Ouest, Francia, 480 p. 
Saint-Charles, J.C., Argüelles-Gamboa, M., 1991, Cerro de la Gruz. Persistencia de un Centro Ceremonial, en Crespo, A.M., Brambila, R. (coords.), Querétaro Prehispánico, Colección Científica del INAH, México, 57-97.

Saint-Charles, J.G., González, F., Almendros, L., 2005, Entierros y ofrendas del epiclásico en el Barrio de la Cruz, San Juan del Río, en Villegas-Molina, M.E. (coord.) Estudios antropológicos de los pueblos otomíes y chichimecas de Querétaro, Centro Regional INAH Querétaro, México, 28-43.

Saint-Charles, J.C., López, A., González, F., 2006, Cerámica del epiclásico en el Cerro de la Cruz, Querétaro, en Merino, Beatriz y Angel García Cook (coords.), La producción alfarera en el México Antiguo, Vol. III, INAH, México, 257-280.

Sandoval, G., 2009, Un espacio autosimilar. El altepetl, el centro ceremonial y la ofrenda, Escuela Nacional de Antropología e Historia, México, Tesis de Licenciatura.

Sanhueza, L, 2004, Estilos tecnológicos e identidades sociales durante el periodo alfarero temprano en Chile central: Una mirada desde la alfarería: Chile, Universidad de Chile, Tesis de Maestría, 83 p.

Sean-Quinn, P., 2013, Ceramic Petrography: The Interpretation of Archaeological Pottery and Related Artefacts in thin Section, Oxford, Archaeopress, 260 p.
Segerstrom, K., 1961, Geología del suroeste del Estado de Hidalgo y del noroeste del Estado de México: Boletín de la Asociación Mexicana de Geólogos Petroleros, 13(3), 147-168.

Sellet, F., 1993, Chaîne opératoire; the concept and its applications: Lithic technology, 18, 106-112.

Solleiro-Rebolledo, E., Sedov S., McClung de Tapia, E., Cabadas, H., Gama-Castro J., Vallejo-Gómez, E., 2006, Spatial variability of environment change in the Teotihuacan Valley during the Late Quaternary: Paleopedological inferences: Quaternary International, 156/157, 13-31.

Stoops, G., 2003, Guidelines for Analysis and Description of Soil and Regolith Thin Sections, Madison, WI, Soil Science Society of America, $184 \mathrm{p}$.

Terrádez, M., 2002, Análisis de componentes principales, (en línea): Cataluña, Universitat Oberta de Catalunya, disponible en <https://www.uoc.edu/in3/emath/docs/ Componentes_principales.pdf $>$, consultado 9 de abril 2018.

Wieder, M., Adan-Bayewitz, D., 1999, Pottery manufacture in early Roman Galilee: a micromorphological study: Catena, 35, 327-341. 